\title{
Microarray Expression Profile Analysis of Long Non-Coding RNAs in Umbilical Cord Plasma Reveals their Potential Role in Gestational Diabetes-Induced Macrosomia
}

\author{
Zhonghua Shi Chun Zhao Wei Long Hongjuan Ding Rong Shen \\ State Key Laboratory of Reproductive Medicine, Nanjing Maternity and Child Health Care Hospital \\ Affiliated to Nanjing Medical University, Nanjing, China
}

\section{Key Words}

GDM $\cdot$ Macrosomia $・$ IncRNA $\cdot$ Microarray $・$ Plasma

\begin{abstract}
Background: Fetal macrosomia and its associated complications are the most frequent and serious morbidities for infants associated with gestational diabetes mellitus (GDM). The associations between long non-coding RNAs (IncRNAs) and macrosomia have been rarely reported; therefore, we investigated the umbilical cord IncRNA profiles in GDM macrosomia. Method: Thirty pairs of GDM macrosomia and normal controls were divided into three subgroups randomly, and the umbilical cord vein blood from each subgroup was mixed, and hybridized to a microarray containing probes representing 33,000 IncRNA genes. Quantitative real-time polymerase chain reaction ( $(P C R)$ was used to validate selected differentially expressed IncRNAs. The gene ontology (GO), pathway and network analysis were performed. Result: The microarray identified 8814 IncRNAs that were expressed in the umbilical cord blood, of which 349 were significantly upregulated and 892 were significantly downregulated (foldchange $\geq 2.0$ ) in GDM group. The highest enriched GOs targeted by downregulated transcripts were biological regulation. Pathway analysis indicated that nine pathways corresponded to downregulated transcripts. Conclusions: Certain IncRNAs that were aberrantly expressed in the umbilical cord blood from GDM macrosomia might play a partial or key role in GDM macrosomia development. This study provided potential targets for treatment of macrosomia and novel insights into macrosomia biology.
\end{abstract}




\section{Cellular Physiology Cell Physiol Biochem 2015;36:542-554 \\ \begin{tabular}{ll|l} 
and Biochemistry & $\begin{array}{l}\text { DOI: 10.1159/000430119 } \\
\text { Published online: May 18, } 2015\end{array}$ & $\begin{array}{l}\text { 2015 S. Karger AG, Basel } \\
\text { www.karger.com/cpb }\end{array}$ \\
\cline { 2 - 3 } Shi &
\end{tabular} \\ Shi et al.: Umbilical Cord IncRNA Expression Profile Analysis of Gestational Diabetes- induced Macrosomia}

\section{Introduction}

Foetal macrosomia is the predominant adverse outcome of gestational diabetes mellitus (GDM), which is usually defined as a birth weight (BW) above the 90th percentile or BW above $4000 \mathrm{~g}[1,2]$. Macrosomia is closely associated with higher rates of cesarean section and sequential use of vacuum and obstetric forceps for vaginal delivery for the mother, and clavicle fracture, intracranial hemorrhage and respiratory distress syndrome for the newborn $[3,4]$. Furthermore, macrosomic babies may have an increased susceptibility to obesity and type-2 diabetes and/or cardiovascular diseases in later life [5,6]. Recently, the increasing prevalence of GDM in pregnant women in many parts of the world could be associated with a parallel increase in macrosomic births. The continuously increasing incidence of gestational diabetes-induced macrosomia during the past three decades in developed and developing countries suggested that it is critical to understand the mechanisms underlying gestational diabetes-induced macrosomia, which will help to reduce the incidence of obstetrical complications and type 2 diabetes [3, 7].

The placenta is an important endocrine organ during human pregnancy, which produces numerous proteins that may promote early embryonic growth [8]. Furthermore, release of these critical proteins from placental tissues into the umbilical circulation presumably contributes to their increased concentration in cord blood and thereby, fetal tissues. These proteins are reported to be involved in accelerating fetal growth [9-11]. Since the umbilical cord vein blood is primarily produced from placental sources, the study of the critical gene products in the umbilical cord vein blood might be help to understand the mechanisms of fetal macrosomia.

Recently, genetic studies have focused on non-coding RNAs. Over the past decade, many studies have reported that non-coding RNAs have important regulatory potentials, both transcriptionally and post transcriptionally [12]. Long non-coding RNAs (lncRNAs) are functional RNAs longer than 200 nucleotides in length. LncRNAs are associated with more than 150 diseases [13], such as preeclampsia [14]. Therefore, LncRNAs are important biological molecules in the mechanisms of disease and are useful for exploring biomarkers for disease diagnosis and treatment. However, the expression of lncRNAs in umbilical cord vein blood and their biological functions in gestational diabetes-induced macrosomia remain unknown.

In this study, we examined the umbilical cord vein blood IncRNA expression profiles of 30 cases of gestational diabetes-induced macrosomia compared with 30 matched non-diabetic macrosomia samples. We then performed internal validations using individual quantitative real-time polymerase chain reaction (qRT-PCR) assays to find a class of functional lncRNAs. Our results demonstrated that lncRNA expression profiles may provide new molecular biomarkers or a new basis for the diagnosis and treatment of gestational diabetes-induced macrosomia.

\section{Materials and Methods}

\section{Ethics statement}

This study was conducted in accordance with the declaration of Helsinki and performed with approval from the Ethics Committee of the Nanjing Maternity and Child Health Care Hospital affiliated to Nanjing Medical University. Written informed consent was obtained from all subjects before enrolment.

\section{Subjects}

Women with GDM, diagnosed by $75 \mathrm{~g}$ oral glucose tolerance test (OGTT) during their 24th to 28th week of gestation at the Obstetrics Department in Nanjing Maternity and Child Health Care Hospital in 2013, were enrolled in this study. According to the IADPSG (The International Association of Diabetes and Pregnancy Study Groups) and ADA (American Diabetes Association) recommendation [15, 16], GDM was diagnosed if any one glucose level was equal to or greater than fasting $5.1 \mathrm{mmol} / \mathrm{L}$, one hour post load 10.0 


\section{Cellular Physiology Cell Physiol Biochem 2015;36:542-554 \begin{tabular}{l|l} 
and Biochemistry $10.1159 / 000430119$ & $\begin{array}{l}\text { Published online: May 18, } 2015 \\
\text { www.karger.com/cpb }\end{array}$ \\
\cline { 2 - 3 }
\end{tabular} \\ Shi et al.: Umbilical Cord IncRNA Expression Profile Analysis of Gestational Diabetes- induced Macrosomia}

Table 1. Maternal and neonatal characteristics of the study population. Data are presented as means \pm SEM. BMI: body mass index; HbA1c: glycated hemoglobin. ${ }^{*} \mathrm{P}<0.05,{ }^{* *} \mathrm{P}<0.01$ versus the control

\begin{tabular}{lcc}
\hline & Control & GDM \\
\hline Cases & 30 & 30 \\
Age (years) & $28.19 \pm 2.30$ & $29.05 \pm 3.05$ \\
Gravidity Parity & 1 & 1 \\
BMI pre-pregnancy $\left(\mathrm{kg} / \mathrm{m}^{2}\right)$ & $21.97 \pm 0.83$ & $22.14 \pm 1.26$ \\
Fasting glucose $(\mathrm{mmol} / \mathrm{L})$ & $4.38 \pm 0.25$ & $5.22 \pm 0.37 * *$ \\
2-hour postprandial glucose (mmol/L) & $6.08 \pm 0.43$ & $7.63 \pm 1.52 * *$ \\
HbA1C (\%) & $5.08 \pm 0.29$ & $5.68 \pm 0.31 *$ \\
Insulin treatment cases & 0 & $4 * *$ \\
Birth Weight (kg) & $3.24 \pm 0.26$ & $4.56 \pm 0.37^{* *}$ \\
Neonatal gender (number of male) & $21(70.00 \%)$ & $23(76.67 \%)$ \\
\hline
\end{tabular}

mmol/L or two hours post load $8.5 \mathrm{mmol} / \mathrm{L}$. Pregnant women with GDM were treated with a strict diet control to maintain the fasting plasma glucose level at less than $5.3 \mathrm{mmol} / \mathrm{L}$ and $2 \mathrm{~h}$ postprandial level at less than $6.7 \mathrm{mmol} / \mathrm{L}$. Insulin treatment was administrated when dietary control could not achieve this goal.

Clinical data and outcomes of GDM women and their paired controls were collected until delivery. The babies of GDM group were diagnosed as macrosomia when their birthweight was equal to or exceeded 4000 $\mathrm{g}$ [17]. The baby birthweight was less than $4000 \mathrm{~g}$ in the control group with normal OGTT. They were chosen on the basis of matched gestational age and gender, and to keep the maternal baseline characteristics similar. The exclusion criteria for both groups included hypertensive disorders, history of type 2 diabetes, smoking, chemical dependency, assisted reproductive technology treatment, multiple pregnancies, fetal congenital anomalies and any other confounding pathologies (including intrahepatic cholestasis of pregnancy, hyperthyroidism and hypothyroidism). Thirty control cases and 30 GDM cases were enrolled in this study ultimately. Maternal and neonatal characteristics are presented in Table 1.

\section{RNA extraction}

Blood samples of the umbilical vein of the control and GDM groups were collected at the time of cesarean or vaginal delivery. Plasma was obtained by centrifugation of EDTA-blood at $1600 \times \mathrm{g}$ for $10 \mathrm{~min}$, and supernatant was centrifuged at $12000 \times \mathrm{g}$ for $5 \mathrm{~min}$ at $4^{\circ} \mathrm{C}$. The control or GDM group was divided into three subgroups randomly, such that every subgroup was a mixture of $10 \mathrm{~mL}$ plasma $(1 \mathrm{~mL}$ from every pregnant woman). In total, $2 \mathrm{~mL}$ clean plasma from each subgroup was filtered through a $0.22-\mu \mathrm{m}$ filter (MILLEXGV; Millipore), and then mixed with $2 \mathrm{~mL}$ TRIZOL reagent and $0.4 \mathrm{~mL}$ chloroform. The mixture was centrifuged at $12000 \times \mathrm{g}$ for $5 \mathrm{~min}$ at $4^{\circ} \mathrm{C}$. The aqueous layer was transferred to a new tube, $1.5 \mathrm{~mL} 70 \%$ ethanol was added, and then applied to an RNeasy minicolumn (Qiagen), according to the manufacturer's recommendations. RNA quantity and quality were measured using a NanoDrop ND-1000. Total RNA was eluted with $20 \mu \mathrm{L}$ RNase-free water after DNase digestion and then stored in liquid nitrogen at $-20^{\circ} \mathrm{C}$ [18].

RNA labeling and Microarray analysis of LncRNA and mRNA expression

Sample labeling and array hybridization were performed according to the Agilent One-Color Microarray-Based Gene Expression Analysis protocol (Agilent Technology), with minor modifications. Briefly, mRNA was purified from total RNA after removal of rRNA (mRNA-ONLY ${ }^{\mathrm{TM}}$ Eukaryotic mRNA Isolation Kit, Epicentre). Each sample was then amplified and transcribed into fluorescent cRNA along the entire length of the transcripts without 3' bias, utilizing a random priming method (Arraystar Flash RNA Labeling Kit, Arraystar). The labeled cRNAs were purified by an RNeasy Mini Kit (Qiagen). The concentration and specific activity of the labeled cRNAs (pmol Cy3/ $\mu \mathrm{g}$ cRNA) were measured using a NanoDrop ND-1000. $1 \mu \mathrm{g}$ of each labeled cRNA was fragmented by adding $5 \mu \mathrm{L} 10 \times$ Blocking Agent and $1 \mu \mathrm{L}$ of $25 \times$ Fragmentation Buffer, then heating at $60^{\circ} \mathrm{C}$ for $30 \mathrm{~min}$; finally $25 \mu \mathrm{l} 2 \times$ GE Hybridization buffer was added to dilute the labeled 


\section{Cellular Physiology Cell Physiol Biochem 2015;36:542-554 \begin{tabular}{l|l} 
and Bioch 10.1159/000430119 & $\begin{array}{l}\text { O 2015 S. Karger AG, Basel } \\
\text { www.karger.com/cpb }\end{array}$ \\
\hline
\end{tabular} \\ Shi et al.: Umbilical Cord IncRNA Expression Profile Analysis of Gestational Diabetes- induced Macrosomia}

cRNA. $50 \mu \mathrm{L}$ of hybridization solution was dispensed into the gasket slide and assembled into the LncRNA expression microarray slide. The slides were incubated for 17 hours at $65^{\circ} \mathrm{C}$ in an Agilent Hybridization Oven. The hybridized arrays were washed, fixed and scanned using an Agilent DNA Microarray Scanner (part number G2505C).

Arraystar Human LncRNA Microarray V3.0 is designed for the global profiling of human LncRNAs and protein-coding transcripts. About 30,586 LncRNAs and 26,109 coding transcripts can be detected by our third-generation LncRNA microarray. 33,045 LncRNAs and 30,215 coding transcripts collected from the most authoritative databases such as, UCSC, NCBI RefSeq, RNAdb, Ensembl, H-invDB and many related literatures, could be detected using the microarray. The microarray work was performed by Kang Chen Biotech, Shanghai, P.R. China [19]. The criteria were as follows: fold-change cut-off: 2.0; fold-change: positive value indicates upregulation in GDM group and negative value indicates downregulation in the control group. Log fold-change means a $\log _{2}$ value of the absolute fold-change. The fold-change and $p$-value were calculated from the normalized expression.

\section{Data analysis}

Agilent Feature Extraction software (version 11.0.1.1) was used to analyze the acquired array images. Quantile normalization and subsequent data processing were performed using the GeneSpring GX v12.1 software package (Agilent Technologies). After quantile normalization of the raw data, LncRNAs and mRNAs that in at least three out of six samples had flags in Present or Marginal ("All Targets Value") were chosen for further data analysis. Differentially expressed LncRNAs and mRNAs with statistical significance between the two groups were identified through P-value/false discovery rate (FDR) and fold change filtering. Hierarchical Clustering and combined analysis were performed using in-house scripts.

\section{Quantitative real-time PCR and statistical Analysis}

The total RNA was isolated using the TRIZOL reagent (Invitrogen, Carlsbad, CA, USA) and then reverse transcribed using PrimeScript ${ }^{\circledR}$ RT reagent Kit with gDNA Eraser (Perfect Real Time) (Takara, Dalian China), according to the manufacture's instructions. The expressions of five upregulated lncRNAs and three downregulated IncRNAs in 60 pregnant women enrolled in this study were measured by qRT-PCR and GAPDH was used as an internal control. The primers are listed in Table 2. The relative expression of LncRNAs was determined by the $2^{-\Delta \Delta \mathrm{Ct}}$ method with GAPDH expression to normalize the data. The expression level of IncRNAs differentially expressed between normal control and GDM women complicated with macrosomia were analyzed using Student's t-test in SPSS (Version 17.0 SPSS Inc). P $<0.05$ was considered statistically significant [20]. The clustering analysis of differentially expressed lncRNAs was performed using the software Cluster 3.0, and the heatmap of the clustered results was generated using the software TreeView.

Table 2. Sequences of PCR primers and specific probes $\left(5^{\prime}-3^{\prime}\right)$ for the detection of five upregulated and three downregulated lncRNAs by real time PCR

\begin{tabular}{lll}
\hline Seqname/Genesymbol & Primer & Sequence \\
\hline ENST00000563895/ & Sense primer & TGCCACTGGAAAAGAATGTGA \\
TCONS_00008033 & Antisense primer & AGTTATGAAGGGTGGAAGTGC \\
uc021tzj.1/ L0C404266 & Sense primer & AAGGGGTGAAGGGAAAGGAG \\
& Antisense primer & ACGTCCTGGTTTCTATAGGGC \\
ENST00000561111/ & Sense primer & GAGGCCAGAGAAAGGAGGAG \\
RP11-316M1.12 & Antisense primer & ATTGAGGGTAGGAGGAGGGT \\
TC0NS_00019669/ & Sense primer & TTCTTCGCCTTCCCGTACTT \\
XL0C_009474 & Antisense primer & GCAGGGAGAATTGCGTCATT \\
ENST00000552367/ & Sense primer & CCGGGACCTTACCTTGTCTT \\
RP11-290L1.3 & Antisense primer & ATGAAGACCGTGGACTGTGT \\
NR_046716/ & Sense primer & CCGGGACCTTACCTTGTCTT \\
MYCBP2-AS1 & Antisense primer & ATGAAGACCGTGGACTGTGT \\
uc00100q.3/ & Sense primer & GAGAACAAAGTGGGTGGCTG \\
BC039516 & Antisense primer & AAAAGGCAGAGAGTCCCACA \\
uc003pol.1/ & Sense primer & ATTGTCTCCAGGGCATGTCA \\
TSG1 & Antisense primer & AGCTCTACATTGGCCCCTTT \\
\hline
\end{tabular}




\section{Cellular Physiology Cell Physiol Biochem 2015;36:542-554 \begin{tabular}{l|l} 
DOI: 10.1159/000430119 & $\begin{array}{l}\text { c } 2015 \text { S. Karger AG, Basel } \\
\text { www.karger.com/cpb }\end{array}$ \\
\hline
\end{tabular} \\ Shi et al.: Umbilical Cord IncRNA Expression Profile Analysis of Gestational Diabetes-}

induced Macrosomia

Table 3. Top 20 upregulated and downregulated IncRNAs between the GDM and Control groups

\begin{tabular}{|c|c|c|c|c|c|c|c|}
\hline \multicolumn{4}{|c|}{$\begin{array}{l}\text { Top } 20 \text { upregulated lncRNAs } \\
\text { (GDM/Control) }\end{array}$} & \multicolumn{4}{|c|}{$\begin{array}{l}\text { Top } 20 \text { downregulated IncRNAs } \\
\text { (GDM/Control) }\end{array}$} \\
\hline Name & Gene symbol & $\mathrm{p}$-value & Fold change & Name & Gene symbol & p-value & Fold change \\
\hline TCONS_00008033 & XLOC_003497 & $2.07304 \mathrm{E}-06$ & 42.2945021 & TCONS_00013456 & XLOC_006112 & $5.4545 \mathrm{E}-07$ & -68.7441146 \\
\hline TCONS_00029007 & XLOC_013931 & 0.000349445 & 32.3694415 & TCONS_00020497 & XLOC_009819 & $5.72029 \mathrm{E}-06$ & -60.6919106 \\
\hline ENST00000526456 & RP11-732A19.5 & $2.9 \mathrm{E}-10$ & 31.2370939 & ENST00000551844 & RP11-394]1.2 & 0.000625569 & -60.5965352 \\
\hline ENST00000452309 & AP003774.7 & $6.30615 \mathrm{E}-05$ & 31.1554936 & ENST00000575838 & CTD-2033A16.3 & $6.1929 \mathrm{E}-07$ & -56.9634939 \\
\hline TCONS_00014805 & XLOC_006881 & $5.91217 \mathrm{E}-05$ & 26.5799454 & ENST00000438858 & GUSBP11 & $1.016 \mathrm{E}-08$ & -55.5134417 \\
\hline TCONS_00011987 & XLOC_005502 & $6.3194 \mathrm{E}-07$ & 24.224465 & ENST00000425124 & BX571672.3 & $3.75 \mathrm{E}-09$ & -54.1936683 \\
\hline ENST00000523459 & RP11-231D20.2 & $4.078 \mathrm{E}-08$ & 20.8059213 & uc003јуу.3 3 & DQ587763 & $6.20626 \mathrm{E}-05$ & -53.0377904 \\
\hline ENST00000453798 & AC073094.4 & $8.00711 \mathrm{E}-05$ & 18.6717007 & ENST00000507274 & RP11-1023L17.1 & $8.7091 \mathrm{E}-07$ & -50.8368441 \\
\hline uc001ody.3 & AF113016 & $8.6426 \mathrm{E}-07$ & 18.0186227 & ENST00000428999 & RP11-347D21.3 & $1.04 \mathrm{E}-09$ & -48.697034 \\
\hline ENST00000563895 & ULK4P3 & $9.8302 \mathrm{E}-06$ & 17.938564 & ENST00000506058 & CTD-2333K2.1 & $1.79 \mathrm{E}-09$ & -41.7446218 \\
\hline ENST00000567688 & CTB-134H23.3 & $1.98677 \mathrm{E}-05$ & 16.822279 & ENST00000560512 & RP11-566K19.4 & $1.5202 \mathrm{E}-07$ & -37.6354183 \\
\hline uc021tz..1 & LOC404266 & $8.11299 \mathrm{E}-05$ & 16.4556438 & ENST00000453039 & AC007383.4 & $2.83 \mathrm{E}-09$ & -36.4905831 \\
\hline uc001lxw.4 & LOC650368 & 0.000266899 & 15.7190915 & ENST00000572491 & RP11-506D12.5 & 0.00024964 & -33.167687 \\
\hline TCONS_00007959 & XLOC_003431 & 0.000904687 & 15.3335138 & ENST00000444346 & AC124944.5 & $1.96484 \mathrm{E}-06$ & -32.1902156 \\
\hline ENST00000558749 & RP11-356M20.3 & $2.956 \mathrm{E}-08$ & 14.1667442 & uc001eqo.1 & FLJ39739 & 0.000112267 & -32.0338723 \\
\hline ENST00000552367 & RP11-290L1.3 & $2.9411 \mathrm{E}-06$ & 14.1039315 & TCONS_00028963 & XLOC_013854 & $2.256 \mathrm{E}-08$ & -27.5824378 \\
\hline ENST00000554946 & NKAPP1 & 0.000359863 & 13.8263617 & ENST00000551846 & RP11-603J24.4 & $1.45831 \mathrm{E}-06$ & -27.4471205 \\
\hline ENST00000514791 & RP11-434D9.2 & 0.000234112 & 13.5389855 & ENST00000531210 & RP11-124G5.3 & $9.2417 \mathrm{E}-07$ & -26.3932212 \\
\hline uc003wvz.1 & AX747586 & $1.3474 \mathrm{E}-07$ & 13.1709853 & ENST00000455455 & CEACAM22P & $1.18609 \mathrm{E}-06$ & -25.7328599 \\
\hline TCONS_00014275 & XLOC_006383 & $1.06054 \mathrm{E}-06$ & 13.0234469 & TCONS_00010272 & XLOC_004737 & $1.1009 \mathrm{E}-07$ & -24.7477169 \\
\hline
\end{tabular}

Fig. 1. A: Volcano Plots of the lncRNA expression profile. The vertical lines correspond to 2.0-fold up- and downregulation and the horizontal line represents a $P$ value of 0.05 . The red point in the plot represents the differentially expressed IncRNAs with statistical significance. B: The scatterplot of lncRNA expression profile, which is useful for assessing the variation or reproducibility between chips.

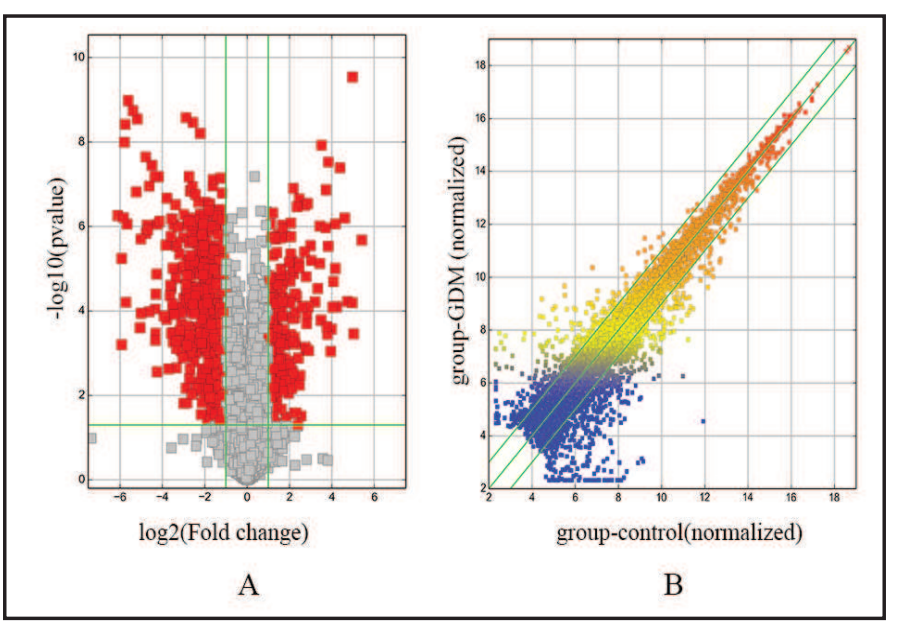

\section{Results}

Differentially expressed IncRNAs

The lncRNA expression profiling data showed that 8814 lncRNAs were expressed in umbilical cord venous plasma from women with gestational diabetes-induced macrosomia (Fig. 1). The lncRNA expression levels between 30 women with gestational diabetes-induced macrosomia and their paired control were compared. 349 lncRNAs were significantly upregulated and 892 lncRNAs were significantly downregulated (fold-change $\geq 2.0$ ) in the GDM group. Hierarchical clustering analysis was used to analyze the relationships between differentially expressed lncRNAs and gestational diabetes-induced macrosomia. XLOC_003497 (Fold change $=42.2945021$ ) was the most significantly upregulated lncRNA and XLOC_006112 (Fold change $=-68.7441146$ ) was the most significantly downregulated IncRNA (Table 3). 


\section{Cellular Physiology Cell Physiol Biochem 2015;36:542-554 \begin{tabular}{ll|l} 
and Biochemistry $10.1159 / 000430119$ & $\begin{array}{l}\text { O 2015 S. Karger AG, Basel } \\
\text { www.karger.com/cpb }\end{array}$ \\
\cline { 2 - 3 }
\end{tabular} \\ Shi et al.: Umbilical Cord IncRNA Expression Profile Analysis of Gestational Diabetes induced Macrosomia}

Fig. 2. A: Volcano Plots of the mRNA expression profile. The vertical lines correspond to 2.0-fold up- and downregulation and the horizontal line represents a $\mathrm{P}$ value of 0.05 . The red point in the plot represents the differentially expressed mRNAs with statistical significance. B: The scatterplot of mRNA expression profile, which is useful for assessing the variation or reproducibility between chips.

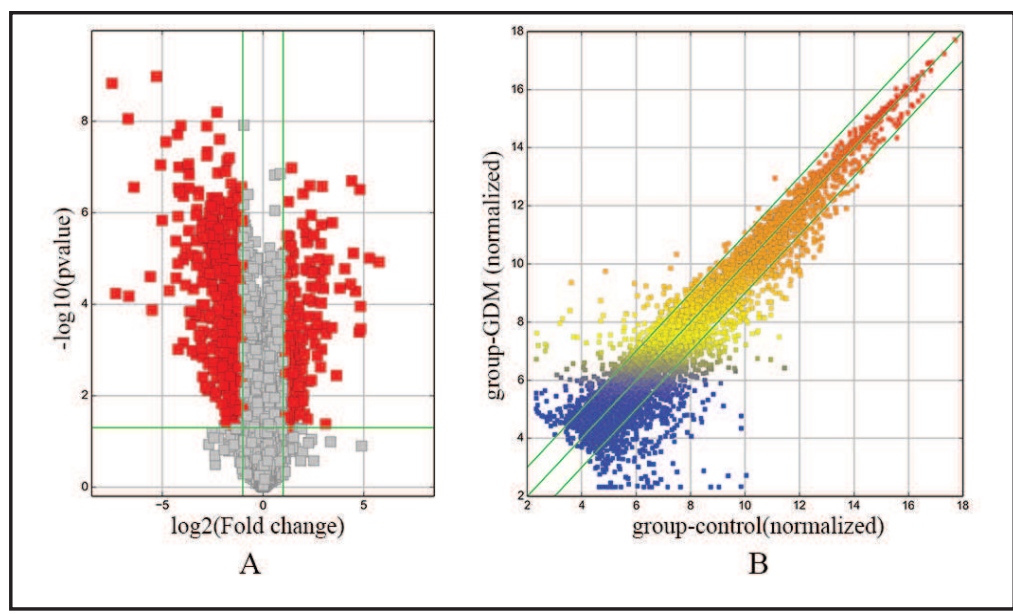

Table 4. Top 20 upregulated and downregulated mRNAs between the GDM and Control groups

\begin{tabular}{lll|llll}
\hline \multicolumn{3}{c}{ Top 20 upregulated mRNAs } & \multicolumn{3}{c}{ Top 20 downregulated mRNAs } \\
(GDM/Control) \\
Name & p-value & Fold change & Name & p-value & Fold change \\
\hline PSMC1 & $1.19266 \mathrm{E}-05$ & 53.7099895 & NCOR1 & $1.47 \mathrm{E}-09$ & -181.5956457 \\
CTTN & $9.77026 \mathrm{E}-06$ & 38.8531151 & HS6ST3 & $5.83345 \mathrm{E}-05$ & -158.8860662 \\
FKBPL & 0.124983684 & 29.5310463 & CDH13 & $8.72 \mathrm{E}-09$ & -104.1977441 \\
CALHM2 & 0.000343302 & 28.6234844 & RAP1B & $2.7612 \mathrm{E}-07$ & -84.7929786 \\
CSTF2 & 0.00011038 & 28.4646818 & ZFP62 & $2.48924 \mathrm{E}-05$ & -48.2547091 \\
ANXA8L1 & $3.0792 \mathrm{E}-07$ & 27.8047765 & DDX41 & 0.000133273 & -45.6019633 \\
PIP4K2B & 0.000405045 & 27.2475278 & IFNK & $1.04 \mathrm{E}-09$ & -39.1646692 \\
CCDC9 & $5.16762 \mathrm{E}-05$ & 24.01927 & KCNA6 & $8.927 \mathrm{E}-08$ & -33.9731582 \\
TMED10 & $7.60058 \mathrm{E}-06$ & 22.2092146 & CES4A & $1.44663 \mathrm{E}-06$ & -32.3346166 \\
ZNF281 & $2.0061 \mathrm{E}-07$ & 21.0673021 & EPHA10 & $2.772 \mathrm{E}-08$ & -28.2929107 \\
EVI2A & $3.61203 \mathrm{E}-05$ & 20.3077566 & PKD2L2 & $5.00393 \mathrm{E}-05$ & -25.1811966 \\
NGF & $1.6677 \mathrm{E}-05$ & 16.5345105 & KRTAP2-4 & $4.1315 \mathrm{E}-06$ & -20.0483282 \\
ENDOV & $4.46006 \mathrm{E}-05$ & 13.9635887 & BEND6 & $2.66115 \mathrm{E}-05$ & -19.8608721 \\
TTC9C & 0.003579749 & 12.4121096 & TOR2A & $1.926 \mathrm{E}-08$ & -18.9131304 \\
MSTN & $1.64817 \mathrm{E}-06$ & 10.7873932 & CD164L2 & $1.28874 \mathrm{E}-05$ & -18.6981245 \\
MLANA & 0.000324381 & 10.6177132 & DDX24 & $1.20091 \mathrm{E}-06$ & -18.625829 \\
TAAR9 & 0.101364682 & 10.1650652 & TAOK2 & 0.000962631 & -18.5305179 \\
KCNQ5 & $1.06593 \mathrm{E}-05$ & 9.3742961 & PRDM16 & $2.8627 \mathrm{E}-07$ & -18.3847604 \\
PSG7 & 0.000438664 & 8.7354014 & GPR173 & $9.924 \mathrm{E}-08$ & -18.0352577 \\
SEZ6L & 0.041271473 & 8.5775066 & ELM01 & $3.4947 \mathrm{E}-07$ & -17.7159464 \\
\hline & & & & & \\
\hline
\end{tabular}

Differentially expressed $m R N A s$

The mRNA expression profiling data showed that 11668 mRNAs were expressed in umbilical cord venous plasma from women with gestational diabetes-induced macrosomia (Fig. 2). The mRNA expression levels between two groups were compared. 252 mRNAs were significantly upregulated in the GDM group and 654 mRNAs were significantly downregulated (fold-change $\geq 2.0$ ). Hierarchical clustering analysis was used to analyze the relationships between differentially expressed mRNAs and gestational diabetes-induced macrosomia. PSMC1 (Fold change $=53.7099895$ ) was the most significantly upregulated mRNA and NCOR1 (Fold change $=181.5956457$ ) was the most significantly downregulated mRNA (Table 4). 


\section{Cellular Physiology Cell Physiol Biochem 2015;36:542-554 \begin{tabular}{l|l} 
DOI: 10.1159/000430119 & $\begin{array}{l}\text { c } 2015 \text { S. Karger AG, Basel } \\
\text { www.karger.com/cpb }\end{array}$ \\
\hline
\end{tabular} \\ Shi et al.: Umbilical Cord IncRNA Expression Profile Analysis of Gestational Diabetes- induced Macrosomia}

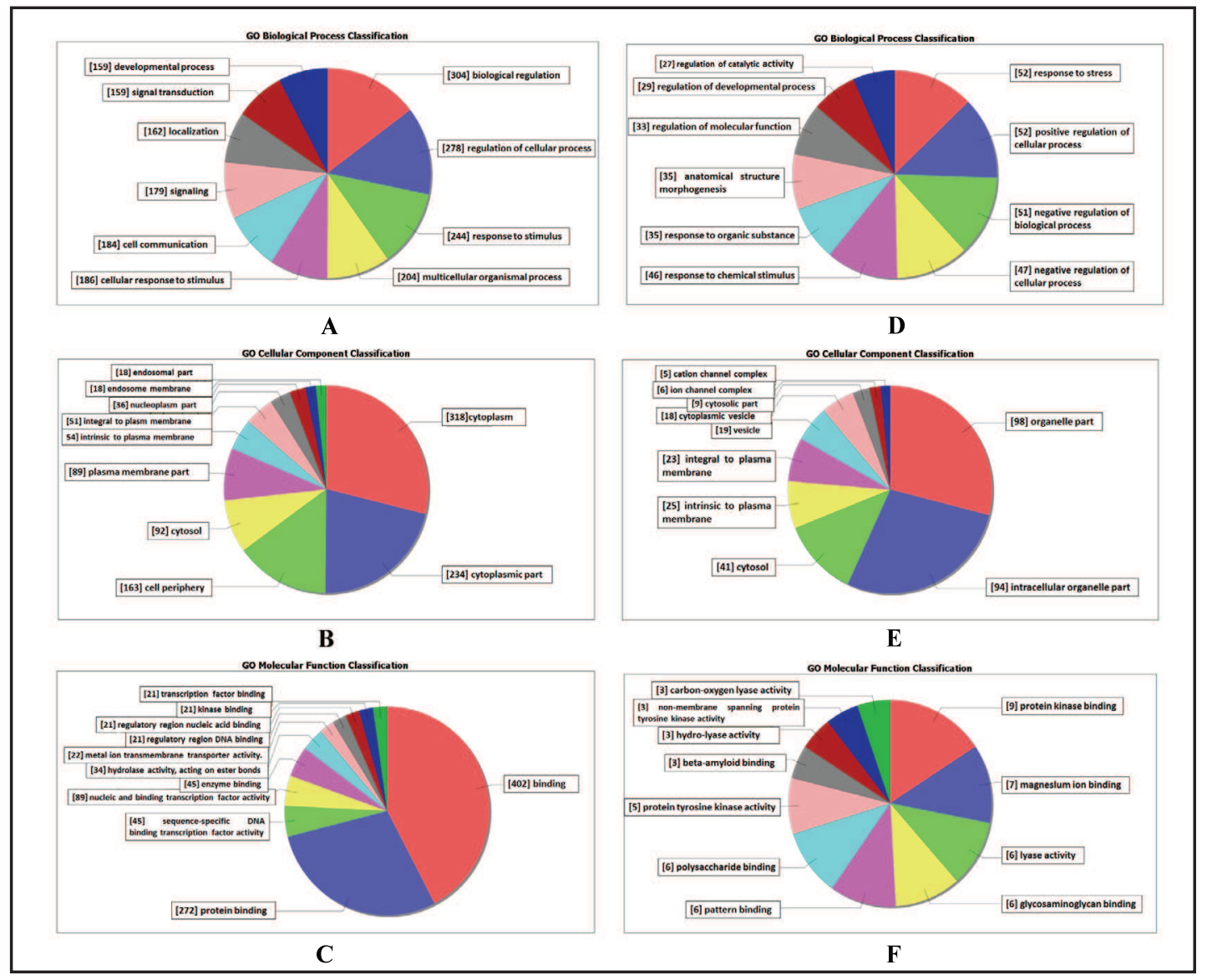

Fig. 3. Gene ontology analysis of mRNAs associated with differentially expressed lncRNAs. Fisher's exact is used to find if there was more overlap between the differentially expressed list and the GO annotation list than would be expected by chance. The p-value denotes the significance of GO terms enrichment in the DE genes. The lower the p-value, the more significant the GO term. A-F, chart shows the top ten counts of the significant enrichment terms. A-C, the highest enriched GOs targeted by downregulated transcripts. A, biological process (BP). B, cellular component (CC). C, molecular function (MF). D-F, the highest enriched GOs targeted by upregulated transcripts. D, biological process (BP). E, cellular component (CC). F, molecular function (MF).

\section{Go analysis}

Gene Ontology (GO) analysis was performed to determine the gene and gene product attributes in biological process, cellular components and molecular functions for the transcripts derived from genes encoding or associated with the differentially expressed IncRNAs. Fisher's exact test was performed to determine if there was more overlap between the differentially expressed list and the GO annotation list than would be expected by chance. The p-value $\leq 0.05$ denoted the significance of GO terms enrichment in the DE genes. The most enriched GOs targeted by the downregulated transcripts were biological regulation (Fig. 3A), cytoplasm (Fig. 3B) and binding (Fig. 3C). The most enriched GOs targeted by the upregulated transcripts were positive regulation of cellular process (Fig. 3D), organelle part (Fig. 3F) and protein kinase binding (Fig. 3E).

\section{Pathway analysis}

Pathway analysis indicated that six pathways corresponded to upregulated transcripts (Fig. 4B). The most enriched network was " $\beta$ cell receptor signaling pathway" comprising four target genes. Pathway analysis indicated that nine pathways corresponded to downregulated transcripts (Fig. 4A). The most enriched network was "mineral absorption" comprising 


\section{Cellular Physiology Cell Physiol Biochem 2015;36:542-554 \begin{tabular}{l|l} 
and Bioch 10.1159/000430119 & $\begin{array}{l}\text { O 2015 S. Karger AG, Basel } \\
\text { www.karger.com/cpb }\end{array}$ \\
\hline
\end{tabular} \\ Shi et al.: Umbilical Cord IncRNA Expression Profile Analysis of Gestational Diabetes- induced Macrosomia}

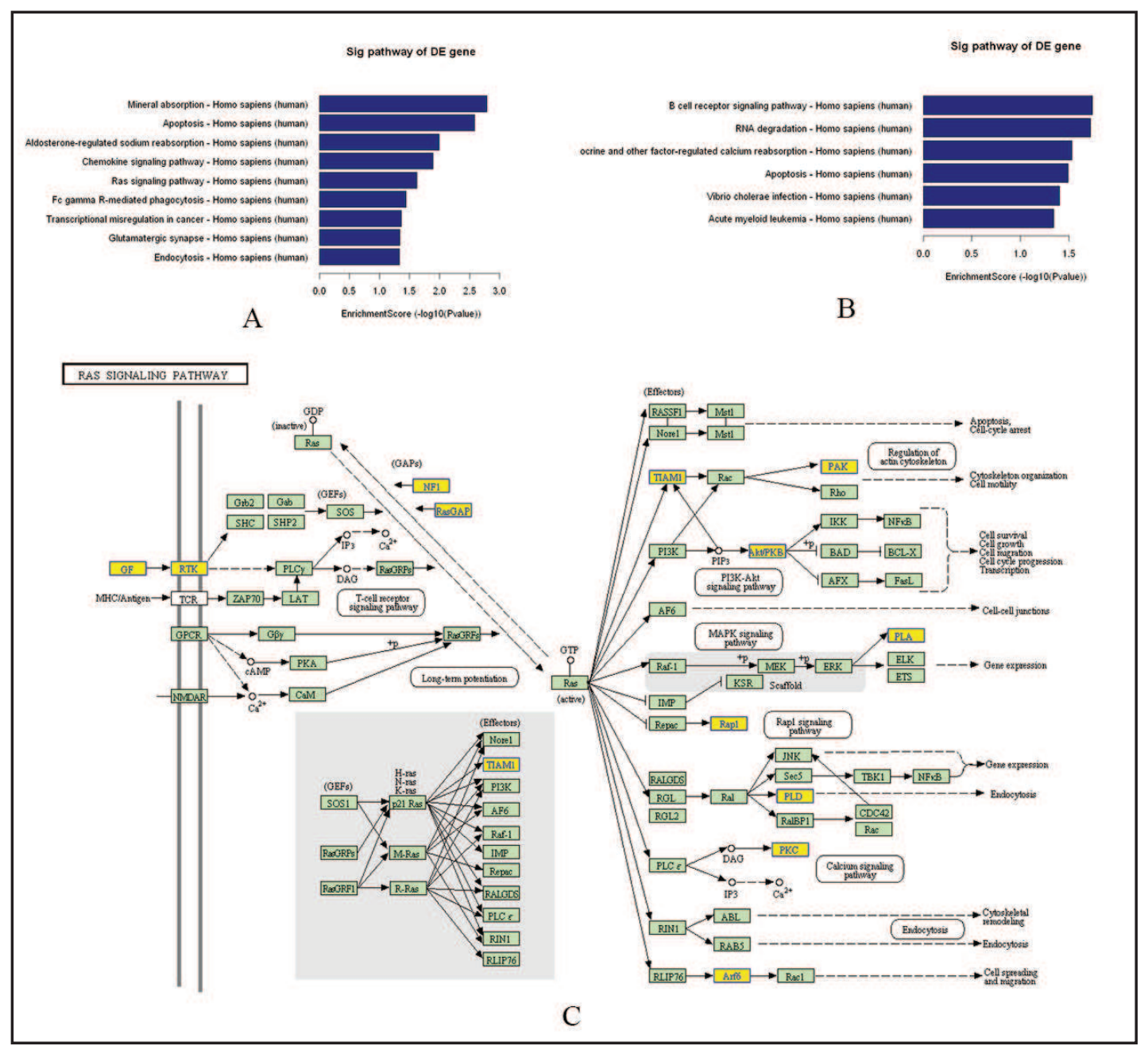

Fig. 4. Pathway analysis mapping genes to KEGG pathways. The p-value (EASE-score, Fisher-P value or Hypergenometric P-value) denotes the significance of the pathway correlated to the conditions. The lower the p-value, the more significant is the pathway. A, Pathways corresponding to downregulated transcripts. $\mathrm{B}$, pathways corresponding to upregulated transcripts. The bar plot in A and B shows the top enrichment score [-log10(P-value)] value of the significantly enriched pathway. C, D, the schematic diagram of the gene category "Ras signaling pathway". Nodes marked in yellow are associated with downregulated genes, green nodes have no significance.

seven target genes. Among these pathways, the gene category "mineral absorption" has been reported to be involved in fetal growth $[21,22]$. The gene category "chemokine signaling pathway" has been reported to be involved in insulin resistance and metabolic phenotype variation [23]. The gene category "Ras signaling pathway" (Fig. 4C) has been reported to be involved in insulin resistance and transplacental transportation of glucose, thus affecting fetal intrauterine growth [24].

\section{$q P C R$}

Five upregulated $\operatorname{lncRNAs}$ and three downregulated $\operatorname{lncRNAs}$ (fold changes $\geq 10$ ), whose potential target genes could be closely related with growth, glucose and lipid metabolism by bioinformatics analysis, were chosen for validation. QPCR was performed to identify the expression levels of the differentially expressed lncRNAs in GDM women with macrosomia, using all 60 plasma samples from women enrolled in this study. The results suggested that the qPCR results were consistent with the microarray data (Fig. 5). 


\section{Cellular Physiology \\ Cell Physiol Biochem 2015;36:542-554 \\ \begin{tabular}{l|l} 
DOI: 10.1159/000430119 & $\begin{array}{l}\text { ○ } 2015 \text { S. Karger AG, Basel } \\
\text { www.karger.com/cpb }\end{array}$ \\
\hline
\end{tabular}

Fig. 5. Screen for the expression of deregulated long noncoding RNAs (LncRNAs) by quantitative PCR assay. Five upregulated and three downregulated LncRNAs were assayed by a quantitative PCR assay and using GAPDH housekeeping gene to normalize the data. **, $\mathrm{p}<0.01$ compared with the control.

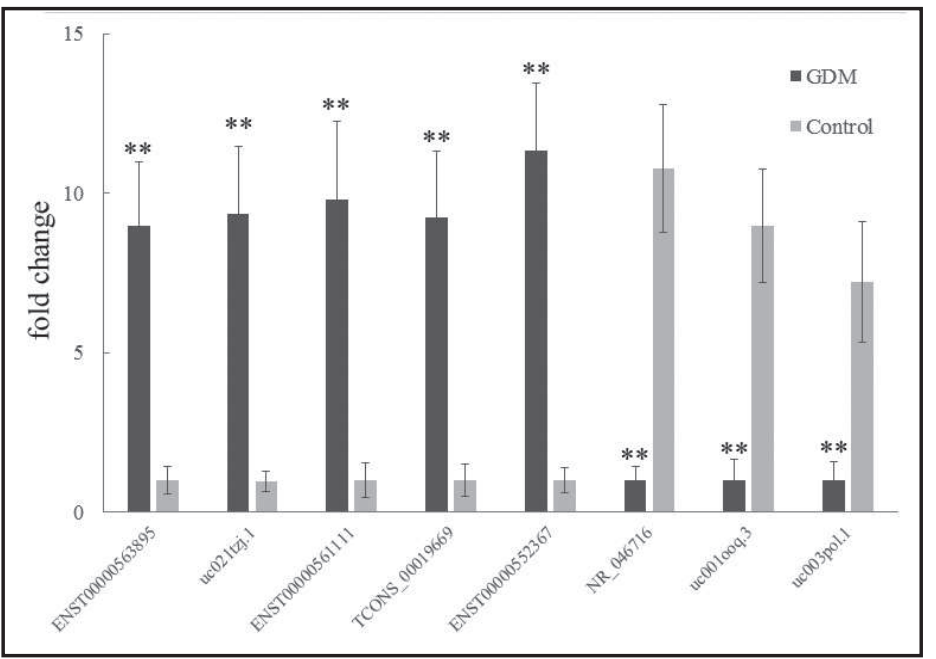

\section{Discussion}

GDM, first diagnosed in pregnancy, complicates about 5\% to $10 \%$ of pregnancies [25]. Macrosomia is the predominant adverse outcome in cases of GDM. It is the main factor linked to reported cases of other complications in GDM [4]. Different from non-diabetic macrosomia, gestational diabetes-induced macrosomia is characterized by asymmetric overgrowth and size increases of insulin-sensitive tissues and organs, especially the adipose tissue, skeletal muscle and liver [26, 27]. Previous studies suggested that GDM women, characterized by hyperglycemia, expose the fetus to higher concentrations of glucose than normal women, forcing the fetus to increase its own insulin production, thus leading to macrosomia [28]. However, there is increasing evidence that, besides the hyperglycemic factor, the releasing of certain critical proteins or nucleic acids from the placenta into the umbilical circulation contributes to their increased concentration in cord blood and thereby fetal tissues, and these factors are reported to be involved in accelerating fetal growth [9-11, 29].

LncRNAs are an emerging class of RNA molecules with a length of more than 200 bases. Studies have revealed that LncRNAs play an essential role in gene silencing, as scaffolds for histone modification, transregulatory elements affecting multiple gene transcription, enhancers to modify gene expression, participators in genomic reprogramming involved in stem cell differentiation and as nucleators to generate the dynamic assembly of the nuclear structure [30]. Recently, some studies have analyzed global changes in LncRNA expression in the pathogenesis of cancer [31], development [32], adipogenesis [33] and preeclampsia [15].

To date, there have been no reports describing LncRNA expression in maternal and fetal circulation system. In our study, we identified the global expression changes in lncRNAs in umbilical vein plasma from GDM-induced macrosomia and paired controls. Since GDMinduced macrosomia is closely related with various factors, such as history of diabetes, BMI before pregnancy, age and genetic reasons, we excluded these confounding factors in the subject enrollment process. Our aim was to study the placenta-derived factors that were released into the umbilical cord vein blood and accelerated fetal growth. Using abundant and varied probes accounting for 33,045 IncRNAs and 30,215 coding transcripts in a microarray, we identified 8814 expressed lncRNAs, among which 259 were upregulated and 892 were downregulated. All raw data discussed in this paper have been deposited in NCBI Gene Expression Omnibus and are accessible with the GEO Series accession number GSE65737 (http://www.ncbi.nlm.nih.gov/geo/query/acc.cgi?acc=GSE65737). Most of these lncRNAs have not been functionally characterized. Five upregulated lncRNAs and three downregulated IncRNAs were further validated using qRT-PCR, and the results were consistent with those of the microarray. Moreover, GO analysis and pathway analysis were performed and a 


\section{Cellular Physiology Cell Physiol Biochem 2015;36:542-554 \\ \begin{tabular}{l|l} 
DOI: 10.1159/000430119 & $\begin{array}{l}\text { ○ } 2015 \text { S. Karger AG, Basel } \\
\text { www.karger.com/cpb }\end{array}$ \\
\hline
\end{tabular} \\ induced Macrosomia}

coexpression network was constructed to study preliminarily the biological functions and potential mechanisms of these differentially expressed lncRNAs in umbilical vein plasma of GDM.

LncRNA ENST00000552367 is an 885 bp lncRNA transcript from the Pleckstrin homology-like domain, family A (PHLDA1) gene, located on Chromosome 12. PHLDA1, also known as $\mathrm{T}$ cell death-associated gene 51 (TADG51), plays an important role in the antiapoptotic effects of insulin-like growth factor-1, which is an important regulator in cell proliferation [34] and gestational diabetes-induced macrosomia [35, 36]. Recently, Basseri [37] suggested that PHLDA1 (TDAG51) expression was inversely correlated with fatty liver in multiple mouse models of hepatic steatosis. TDAG51(-/-) mice fed a chow diet exhibited greater body and adipose deposition, had reduced energy expenditure, displayed matureonset insulin resistance, and was predisposed to hepatic steatosis. Taken together, TDAG51 is involved in energy homeostasis, especially in regulating lipogenesis in liver and adipose tissue, and may constitute a novel therapeutic target for the treatment of obesity and insulin resistance. The fold change of upregulated LncRNA ENST00000552367 was 14.1039315. Coincidentally, PHLDA1 (TDAG51), the target gene of LncRNA ENST00000552367 was also identified in the significantly downregulated mRNAs list in this study (fold change = 3.7422605 , $p$ value $=1.65074 \mathrm{E}-06$ ). This evidence could shed light on the potential roles of LncRNA ENST00000552367 and PHLDA1 (TDAG51) in gestational diabetes-induced macrosomia. LncRNA uc021tzj.1 is a 14,121 bp IncRNA transcript from the HOXB-AS3/ HOXB3/HOXB5/HOXB6 gene, located on Chromosome 17. HOXB-AS3, HOXB3, HOXB5 and HOXB6 are members of homeobox transcription factors family, which are important in differentiation phenotypes of pancreatic beta-cells, insulin resistance [38], and for regulating adipose tissue formation and loss [39]. Furthermore, HOXB3, the target gene of LncRNA uc021tzj.1, was also identified among the differentially expressed mRNAs list (fold change $=2.4270548, \mathrm{p}$ value $=2.50138 \mathrm{E}-06)$. LncRNA RP11-316M1.12 is a $999 \mathrm{bp}$ lncRNA transcript from the ceramide synthase 2 (CERS2) gene, located on Chromosome 1. Raichur [37] demonstrated that insufficiency of CERS2 led to hepatic steatosis and insulin resistance. CERS2 could become a therapeutic target for treating metabolic diseases associated with obesity. LncRNA XLOC_009474 is a 11,954 bp IncRNA transcript from the metastasis associated lung adenocarcinoma transcript 1 (MALAT1) gene, located on Chromosome 1. Liu [40] showed that MALAT1, also known as noncoding nuclear-enriched abundant transcript 2 (NEAT2), could regulate cell proliferation and migration. MALAT1 upregulation represents a critical pathogenic mechanism for diabetes-induced microvascular dysfunction. Cooper [41] suggested that MALAT1 associates with SRp40 to regulate splicing of PPAR $\gamma 2$ (peroxisome proliferator-activated receptor $\gamma 2$ ) during adipogenesis in 3T3-L1 Cells.

To understand the functions of the IncRNAs and the mechanism by which they exert their roles, pathway analysis were performed to study the differentially expressed lncRNAs. Nine pathways corresponded to downregulated transcripts and six pathways corresponded to upregulated transcripts. Among these pathways, the gene category "mineral absorption" has been reported to be involved in fetal growth $[21,22]$. The gene category "chemokine signaling pathway" has been reported to be involved in insulin resistance and metabolic phenotype variation [23]. The gene category "Ras signaling pathway" has been reported to be involved in the insulin resistance and transplacental transportation of glucose, thus affecting fetal intrauterine growth [24].

This study has highlighted the critical role of the materno-feto-placental communication involved in the fetal weight gain in macrosomic babies. The expression profiles of umbilical cord vein plasma, and GO analysis, signal pathway analysis and lncRNA classification analysis, will help us to understand the potential mechanisms of the development of gestational diabetes-induced macrosomia. Furthermore, this study focused, for the first time, on the molecular mechanisms of gestational diabetes-induced macrosomia at the IncRNA level. In addition, we showed that IncRNA ENST00000552367, which is associated with PHLDA1, plays an important role in the anti-apoptotic effects of insulin-like growth factor- 1 , which is an important regulator in cell proliferation and gestational diabetes-induced macrosomia. It 


\section{Cellular Physiology Cell Physiol Biochem 2015;36:542-554 \\ \begin{tabular}{ll|l} 
and Biochemistry $10.1159 / 000430119$ & $\begin{array}{l}\text { P } 2015 \text { S. Karger AG, Basel } \\
\text { Pwww.karger.com/cpb }\end{array}$ \\
\cline { 2 - 3 }
\end{tabular} \\ Shi et al.: Umbilical Cord IncRNA Expression Profile Analysis of Gestational Diabetes- induced Macrosomia}

is suggested that IncRNAs may exert their functions by regulating the transcription of their related protein-coding genes in gestational diabetes-induced macrosomia. However, further work, including functional and mechanistic experiments, is needed to elucidate the potential roles of umbilical cord vein lncRNAs in gestational diabetes-induced macrosomia.

\section{Acknowledgements}

This work was supported by grants from the National Natural Science Foundation of China [grant numbers 81100436], the State Key Laboratory of Reproductive Medicine Fund [grant number SKLRM-KF-201109], the Nanjing Medical Technology Development Project [grant numbers YKK14126] and Nanjing Medical Young Investigators Project [grant number QRX11211].

\section{Disclosure Statement}

All authors have no conflicts of interest to declare.

\section{References}

1 American College of Obstetricians and Gynecologists: ACOG Practice Bulletin Fetal Macrosomia, 2000.

2 Silverman BL, Landsberg L, Metzger BE: Foetal hyperinsulinism offspring of diabetic mothers: association with the subsequent development of childhood obesity. Ann N Y Acad Sci 1993;699:36-45.

3 Koyanagi A, Zhang J, Dagvadorj A, Hirayama F, Shibuya K, Souza JP, Gülmezoglu AM: Macrosomia in 23 developing countries: an analysis of a multicountry, facility based, cross-sectional survey. Lancet 2013;381:476-483.

4 Mitanchez D: Foetal and neonatal complications in gestational diabetes: perinatal mortality, congenital malformations, macrosomia, shoulder dystocia, birth injuries, neonatal complications. Diabetes Metab 2010;36:617-627.

5 Yu ZB, Han SP, Zhu GZ, Zhu C, Wang XJ, Cao XG, Guo XR: Birth weight and subsequent risk of obesity: a systematic review and meta-analysis. Obes Rev 2011;12:525-542.

6 Kim C, Newton KM, Knopp RH: Gestational diabetes and the incidence of type 2 diabetes: a systematic view. Diabetes Care 2002;25:1862-1868.

7 Liu J, Leng J, Tang C, Liu G, Hay J, Wang J, Wen S, Li Z, She Y: Maternal glucose level and body mass index measured at gestational diabetes mellitus screening and the risk of macrosomia: results from a perinatal cohort study. BMJ Open 2014;4:e004538.

8 Handwerger S, Freemark M: The roles of placental growth hormone and placental lactogen in the regulation of human foetal growth and development. J Pediatr Endocrinol Metab 2000;13:343-356.

9 Jokic M, Guillois B, Cauquelin B, Giroux JD, Bessis JL, Morello R, Levy G, Ballet JJ: Fetal distress increases interleukin- 6 and interleukin-8 and decreases tumour necrosis factor-alpha cord blood levels in noninfected full-term neonates. BJOG 2000;107:420-425.

10 Malamitsi-Puchner A, Protonotariou E, Boutskiou T, Makrakis E, Sarandakou A, Creatsas G: The influence of the mode of delivery on circulating cytokine concentrations in the perinatal period. Early Hum Dev 2005;81:387-392.

11 Duncombe G, Veldhuizen RAW, Gratton RJ, Han VKM, Richardson BS: IL- 6 and TNF $\alpha$ across the umbilical circulation in term pregnancies: relationship with labour events. Early Hum Dev 2010;86:113-117.

12 Ponting CP, Oliver PL, Reik W: Evolution and functions of long non-coding RNAs. Cell 2009;136:629-641.

13 Chen G, Wang Z, Wang D, Qiu C, Liu M, Chen X, Zhang Q, Yan G, Cui Q: LncRNADisease: a database for longnon-coding RNA-associated diseases. Nucleic Acids Res 2013;41:D983-986.

14 He X, He Y, Xi B, Zheng J, Zeng X, Cai Q, Yu O, Wang C, Zhou X, Huang H, Deng W, Xin S, Huang Q Liu H: LncRNAs Expression in Preeclampsia Placenta Reveals the Potential Role of LncRNAs Contributing to Preeclampsia Pathogenesis. PLoS ONE 2013;8: e81437. 


\section{Cellular Physiology Cell Physiol Biochem 2015;36:542-554 \begin{tabular}{l|l} 
and Biochemistry $10.1159 / 000430119$ & $\begin{array}{l}\text { Published online: May 18, } 2015 \\
\text { www.karger.com/cpb }\end{array}$ \\
\cline { 2 - 3 }
\end{tabular}}

Shi et al.: Umbilical Cord IncRNA Expression Profile Analysis of Gestational Diabetesinduced Macrosomia

15 American Diabetes Association. Diagnosis and classification of diabetes mellitus. Diabetes Care 2011;34:s62-s69.

16 International Association of Diabetes and Pregnancy Study Groups Consensus Panel. International association of diabetes and pregnancy study groups recommendations on the diagnosis and classification of hyperglycemia in pregnancy. Diabetes Care 2010;33:676-682.

17 Farrar D, Duley L, Medley N, Lawlor DA: Different strategies for diagnosing gestational diabetes to improve maternal and infant health. Cochrane Database Syst Rev 2015;1:CD007122.

18 Tsui NB, Ng EK, Lo YM: Stability of endogenous and added RNA in blood specimens, serum, and plasma. Clin Chem 2002;48:1647-1653.

19 Xiaoju H, Yinyan H, Binrong X, Jiusheng Z, Xiaoming Z, Qinhua C, Yu OuY, Chen W, Xiaofei Z, Huiying H, Wei D, Siming X, Qixiang H, Huai L: LncRNAs expression in preeclampsia placenta reveals the potential role of LncRNAs contributing to preeclampsia pathogenesis. PLoS ONE 2013;8:e81437.

20 Ren S, Peng Z, Mao JH, Yu Y, Yin C, Cao X, Cui Z, Zhang J, Yi K, Xu W, Chen C, Wang F, Guo X, Lu J, Yang J, Wei M, Tian Z, Guan Y, Tang L, Xu C, Wang L, Gao X, Tian W, Wang J, Yang H, Wang J, Sun Y: RNA-seq analysis of prostate cancer in the Chinese population identifies recurrent gene fusions, cancer-associated long noncoding RNAs and aberrant alternative splicings. Cell Res 2012;22:806-821.

21 Al-Saleh E, Nandakumaran M, Al-Rashdan I, Al-Harmi J, Al-Shammari M: Maternal-foetal status of copper, iron, molybdenum, selenium and zinc in obese gestational diabetic pregnancies. Acta Diabetol 2007;44:106-113.

22 Asemi Z, Karamali M, Esmaillzadeh A: Effects of calcium-vitamin D co-supplementation on glycaemic control, inflammation and oxidative stress in gestational diabetes: a randomised placebo-controlled trial. Diabetologia 2014;57:1798-1806.

23 Urbanek M, Hayes MG, Lee H, Freathy RM, Lowe LP, Ackerman C, Jafari N, Dyer AR, Cox NJ, Dunger DB, Hattersley AT, Metzger BE, Lowe WL Jr: The role of inflammatory pathway genetic variation on maternal metabolic phenotypes during pregnancy. PLoS One 2012; 7:e32958.

24 Liu B, Xu Y, Voss C, Qiu FH, Zhao MZ, Liu YD, Nie J, Wang ZL: Altered protein expression in gestational diabetes mellitus placentas provides insight into insulin resistance and coagulation/fibrinolysis pathways. PLoS One 2012; 7:e44701.

25 Metzger BE, Buchanan TA, Coustan DR, de Leiva A, Dunger DB, Hadden DR, Hod M, Kitzmiller JL, Kjos SL, Oats JN, Pettitt DJ, Sacks DA, Zoupas C: Summary and recommendations of the Fifth International Workshop-Conference on Gestational Diabetes Mellitus. Diabetes Care 2007;30:S251-260.

26 Tyrala EE: The infant of the diabetic mother. Obstet Gynecol Clin North Am 1996;23:221-241.

27 Anna V, van der Ploeg HP, Cheung NW, Huxley RR, Bauman AE: Sociodemographic correlates of the increasing trend in prevalence of gestational diabetes mellitus in a large population of women between 1995 and 2005.Diabetes care 2008;31:2288-2293.

28 Pridjian G, Benjamin TD: Update on gestational diabetes. Obstet Gynecol Clin North Am 2010;37:255-267.

29 Liu L, Zhang X, Rong C, Rui C, Ji H, Qian YJ, Jia R, Sun L. Distinct DNA methylomes of human placentas between pre-eclampsia and gestational diabetes mellitus. Cell Physiol Biochem 2014;34:1877-1889.

30 Nagano T, Fraser P: No-nonsense functions for long noncoding RNAs. Cell 2011;145:178-181.

31 Qiu MT, Hu JW, Yin R, Xu L: Long noncoding RNA: an emerging paradigm of cancer research. Tumour Biol 2013;34:613-620.

32 Klattenhoff CA, Scheuermann JC, Surface LE, Bradley RK, Fields PA, Steinhauser ML, Ding H, Butty V, Torrey L, Haas S, Abo R, Tabebordbar M, Lee R, Burge CB, Boyer LA: Braveheart, a long noncoding RNA required for cardiovascular lineage commitment. Cell 2013;152:570-583.

33 Sun L, Goff LA, Trapnell C, Alexander R, Lo KA, Hacisuleyman E, Sauvageau M, Tazon-Vega B, Kelley DR, Hendrickson DG, Yuan B, Kellis M, Lodish HF, Rinn JL. Long noncoding RNAs regulate adipogenesis. Proc Natl Acad Sci USA 2013;110:3387-3392.

34 Toyoshima Y, Karas M, Yakar S, Dupont J, Lee H, LeRoith D: TDAG51 mediates the effects of insulin-like growth factor I (IGF-I) on cell survival. J Biol Chem 2004;279:25898-25904.

35 Lauszus FF, Klebe JG, Flyvbjerg A: Macrosomia associated with maternal serum insulin-like growth factor-I and -II in diabetic pregnancy. Obstet Gynecol 2001;97:734-741.

36 Luo ZC, Nuyt AM, Delvin E, Audibert F, Girard I, Shatenstein B, Cloutier A, Cousineau J, Djemli A, Deal C, Levy E, Wu Y, Julien P, Fraser WD: Maternal and fetal IGF-I and IGF-II levels, fetal growth, and gestational diabetes. J Clin Endocrinol Metab 2012;97:1720-1728. 
37 Raichur S, Wang ST, Chan PW, Li Y, Ching J, Chaurasia B, Dogra S, Öhman MK, Takeda K, Sugii S, PewznerJung Y, Futerman AH, Summers SA: CerS2 haploinsufficiency inhibits $\beta$-oxidation and confers susceptibility to diet-induced steatohepatitis and insulin resistance. Cell Metab 2014;20:687-695.

38 Mizusawa N, Hasegawa T, Ohigashi I, Tanaka-Kosugi C, Harada N, Itakura M, Yoshimoto K: Differentiation phenotypes of pancreatic islet beta- and alpha-cells are closely related with homeotic genes and a group of differentially expressed genes. Gene 2004;331:53-63.

39 Dankel SN, Fadnes DJ, Stavrum AK, Stansberg C, Holdhus R, Hoang T, Veum VL, Christensen BJ, Våge V, Sagen JV, Steen VM, Mellgren G: Switch from stress response to homeobox transcription factors in adipose tissue after profound fat loss. PLoS One 2010;5:e11033.

40 Liu JY, Yao J, Li XM, Song YC, Wang XQ, Li YJ, Yan B, Jiang Q: Pathogenic role of lncRNA-MALAT1 in endothelial cell dysfunction in diabetes mellitus. Cell Death Dis 201430;5:e1506.

41 Cooper DR, Carter G, Li P, Patel R4, Watson JE5, Patel NA6: Long Non-Coding RNA NEAT1 Associates with SRp40 to Temporally Regulate PPAR 2 Splicing during Adipogenesis in 3T3-L1 Cells. Genes (Basel) 2014;5:1050-1063. 